\title{
Pathways into ecstasy use: The role of prior cannabis use and ecstasy availability
}

\author{
Petra Zimmermann ${ }^{\mathrm{a}, \mathrm{b}, *}$, Hans-Ulrich Wittchen ${ }^{\mathrm{a}, \mathrm{b}}$, Florian Waszak ${ }^{\mathrm{c}}$, Agnes Nocon ${ }^{\mathrm{a}}$, Michael \\ Höfler ${ }^{\text {a }}$, Roselind Lieb ${ }^{\text {a }}$
}

a Max Planck Institute of Psychiatry, Clinical Psychology and Epidemiology, Kraepelinstrasse 2, 80804 Munich, Germany

b Technical University of Dresden, Clinical Psychology and Psychotherapy, Chemnitzer Str. 46, 01187 Dresden, Germany

c Max Planck Institute for Human Cognitive and Brain Sciences, Department of Psychology, Amalienstr. 33, 80799 Munich, Germany

\begin{abstract}
Aim: To explore the role of cannabis use for the availability of ecstasy as a potential pathway to subsequent first ecstasy use.

Methods: Baseline and 4-year follow-up data from a prospective-longitudinal community study of originally 3021 adolescents and young adults aged 14-24 years at baseline were assessed using the standardized M-CIDI and DSM-IV criteria.

Results: Baseline cannabis users reported at follow-up more frequent access to ecstasy than cannabis non-users. Higher cannabis use frequencies were associated with increased ecstasy availability reports. Logistic regression analyses revealed that cannabis use and availability of ecstasy at baseline are predictors for incident ecstasy use during the follow-up period. Testing simultaneously the impact of prior cannabis use and ecstasy availability including potential confounders, the association with cannabis use and later ecstasy use was confirmed $(\mathrm{OR}=6.3 ; 95 \% \mathrm{CI}=3.6-10.9)$. However, the association with ecstasy availability was no longer significant $(\mathrm{OR}=1.2 ; 95 \% \mathrm{CI}=0.3-3.9)$.

Conclusions: Results suggest that cannabis use is a powerful risk factor for subsequent first onset of ecstasy use and this relation cannot be sufficiently explained by availability of ecstasy in the observation period.
\end{abstract}

Keywords: Ecstasy; Cannabis; Risk factor; Availability; Incidence

\section{Introduction}

Cannabis is the most frequently used illegal substance in the Western world (e.g., Anthony et al., 1994; Baumann and Phongsavan, 1999; Hall et al., 1999; Kraus and Augustin, 2001; Perkonigg et al., 2004; Smart and Ogborne, 2000; Sydow et al., 2001). Among the harmful consequences of cannabis use, strong associations between cannabis use and the secondary initiation of hard drug use have often been reported suggesting cannabis use as a potential risk factor for the onset of the use of other illegal drugs (e.g., Adler and Kandel, 1981; Cohen and Sas, 1997; Degenhardt et al., 2001; Fergusson and Horwood, 2000; Hall et al., 2001; Kandel and Faust, 1975; Kandel et al., 1992; Kandel, 2003; McCoun, 1998; Yamaguchi and Kandel, 1984a,b). This finding is in accordance with the "concept of stages", which describes a regular sequence in the stages of progression in drug involvement. Individuals are unlikely to experiment with cannabis without having used alcohol and tobacco before, and, in turn, very fewtry illegal drugs other than cannabis, such as cocaine or heroin without prior use of cannabis (Adler and Kandel, 1981; Hall et al., 2001; Kandel and Faust, 1975; Kandel and 
Yamaguchi, 1993; Kandel et al., 1992; Kandel, 2003). Based on the observation of temporal progression, cannabis has often been called a 'stepping stone' or a 'gateway' assuming that cannabis is a causal risk factor for the use of other illegal drugs (e.g., Cohen and Sas, 1997; Fergusson and Horwood, 1997, 2000; Hall et al., 2001; Kandel, 2003; McCoun, 1998; Yamaguchi and Kandel, 1984a,b).

Nonetheless, the role of cannabis in the sequence of illegal drug use remains controversial as there is also evidence for alternative hypotheses assuming a non-causal relationship. These concepts attribute the observed associations to other underlying factors, such as a shared genetic vulnerability, a drug use propensity/drug-taking disposition, or (a progression to) a more general deviant behavior pattern. In this perspective, the order in drug use initiation is explained by the order in which adolescents have access to the drugs with cannabis being the most available illegal substance in western societies (Agrawal et al., 2004; Goode, 1974; Hays et al., 1987; Huba et al., 1981; McCoun, 1998; Morral et al., 2002; Pudney, 2003).

According to the 'gateway' concept, several mechanisms of how cannabis may cause the use of other illegal drugs have been suggested. Assumed mechanisms are, e.g., physiological and neurochemical sensitization processes (Cadoni et al., 2001; McCoun, 1998; Tanda et al., 1997; Tanda and Goldberg, 2003; Wickelgren, 1997) or the perception of cannabis effects as pleasant and as presumably not hazardous, increasing the curiosity to experiment with other illegal drugs (McCoun, 1998). A further mechanism that has been discussed is that cannabis users move into a social environment in which the use of cannabis but also the use of other illegal drugs is more likely with respect to social learning processes and a high encouragement to use illegal drugs (Cohen and Sas, 1997; Degenhardt et al., 2001; Fergusson and Horwood, 2000; Goode, 1974; McCoun, 1998). In this context, Hall et al. (2001) emphasize affiliation with drug using peers, socialization with an illegal drug subculture, and involvement in illegal drug markets, which frequently are the same for cannabis and other illegal drugs. Johnson (1973), for example, reported a positive correlation between cannabis use and having at least one friend who uses other illegal drugs.

Within this social context, cannabis and different kinds of other illegal drugs are expected to be more easily available increasing the risk for the first exposure opportunity and for the first actual use of these other illegal drugs among cannabis users (Goode, 1974; McCoun, 1998; Wagner and Anthony, 2002). The relevance of this factor is supported by a series of studies that show variations in the sequence of drug use to depend on the availability of drugs (see Hall et al., 2001). Robins (1993) showed, e.g., that since heroin was easier available for young American soldiers in Vietnam due to military rules against selling alcohol to soldiers under 21 , heroin was frequently used before alcohol. Goode (1974) reported that in the US prior to 1914, when narcotics were over-the-counter patent medicines, or among physicians in the $60 \mathrm{~s}$ who had easy access to these substances, narcotic addiction emerged without previous marijuana use.

There is a range of studies on cannabis and other illegal drugs dealing with the hypotheses on pathways mentioned above (e.g., Agrawal et al., 2004; Cohen and Sas, 1997; Degenhardt et al., 2001; Fergusson and Horwood, 2000; Yamaguchi and Kandel, 1984b). However, the particular relationship between cannabis and ecstasy, a 3,4-methylendioxy-N-methylamphetamin (MDMA), has to our knowledge never been studied systematically with respect to the availability of ecstasy as possible pathway from cannabis to subsequent ecstasy use. Recent findings in clinical samples have highlighted the clinical significance of ecstasy and demonstrated a considerable number of problems associated with ecstasy use: e.g., acute harmful somatic and mental consequences, the development of dependence, cognitive 
impairment, and the evidence of neurotoxic effects damaging the serotonergic and dopaminergic system (Jansen, 1999; Parrott, 2001; Parrott et al., 1998; Thomasius et al., 1997; Tuchtenhagen et al., 2000). Some of these adverse effects were also confirmed even in community samples of low dose users of ecstasy (Schuster et al., 1998).

After cannabis, ecstasy has become the most commonly consumed illegal drug in the European Union (EU) with lifetime rates ranging between 0.5 and 5.0\% among the total adult population (European Monitoring Centre for Drugs and Drug Addiction (EMCDDA, 2003)). The World Health Organization (WHO, 1996) acknowledged that in some countries ecstasy and similar substances have become an established part of youth culture (WHO, 1996). Consistent with a considerable increase of incidence rates of ecstasy use and disorders in Germany, a cumulative lifetime prevalence of $9.1 \%$ among adolescents and young adults aged 17-28 years has been described (Lieb et al., 2002; Schuster et al., 1998; Sydow et al., 2002). Similar findings were reported by Degenhardt et al. (2004) with 12-month prevalences of ecstasy use of $5.0 \%$ among 14 - to 19 -year-old and $10.4 \%$ among 20 - to 29 -year-old Australians. Furthermore, the same studies also highlighted strong associations of ecstasy and cannabis use (Degenhardt et al., 2004; Perkonigg et al., 1999; Smit et al., 2002; Sydow et al., 2001, 2002).

This paper explores the role of cannabis use for the availability of ecstasy as a potential pathway to subsequent first ecstasy use by examining (1) the relation of cannabis use to the subsequent first onset of ecstasy use, focusing on (2) the impact of cannabis use at baseline in predicting the availability of ecstasy 4 years later, and (3) the combined effects of cannabis use and ecstasy availability at baseline in predicting the first onset of ecstasy use during follow-up. The analyses refer to a representative community sample of initially over 3000 adolescents and young adults from Munich, Germany. As retrospective analyses based on cross-sectional data might be distorted by recall and response biases, prospective analyses covering a 4-year follow-up period have been performed.

\section{Methods}

\subsection{Sample}

Data from this report come from the Early Developmental Stages of Psychopathology study (EDSP), a prospective survey of the onset, persistence, and correlates of DSM-IV mental disorders, substance use disorders as well as substance use in a representative sample of adolescents and young adults in Munich, Germany. The EDSP study consists of a baseline survey and two follow-up surveys. The baseline sample was drawn randomly from the 1994 government registries of all residents in the age range 14-24 in metropolitan Munich and the surrounding counties. In this longitudinal panel study with special interest in early developmental stages of psychopathology, the 14- to 15-year-olds were sampled at twice and the 22- to 24-year-old at half the probability of the subjects 16-21 years of age. A total of 3021 respondents were interviewed at baseline (T0) with a response rate of $71 \%$. For adolescents younger than 18 years, which are not of full age in Germany, consent to participate was obtained from the parents. The complete sample consists of white west European adolescents and young adults with German nationality. At baseline, almost threequarter of the participants were students, $36 \%$ at the secondary level and $26 \%$ at university. $20 \%$ of the participants were employed. $62 \%$ of the participants were living with their parents, $23 \%$ were living alone, and $12 \%$ were living with their partner/spouse. Nearly all $(96.3 \%)$ were never married. The majority of the respondents were classified as middle class $(59 \%)$ or upper middle class $(28.3 \%)$, reflecting the population of Munich. 
The first follow-up study (T1) was conducted only for subjects from 14 to 17 years of age at baseline, whereas the second follow-up study (T2) was conducted for all subjects. In the first follow-up, on average 20 months after baseline, a total of 1228 interviews were completed (response rate: $88 \%$ ). Of the 3021 subjects from the baseline-study, a total of 2548 were interviewed at the second follow-up (about 42 months after baseline; response rate: $84 \%$ ). Most frequent reasons for non-response at baseline as well as at the second follow-up were refusal (18.2 and 9.2\%, respectively), lack of time (3.3 and 1.5\%), and failure to contact (3.1 and $2.7 \%$ ). Few subjects were deceased, chronically hospitalised or under arrest (4.4 and $2.6 \%$, respectively). Noteworthy changes in socio-demographic characteristics were found for school/employment status (T2: secondary school: 13\%, employed: $36 \%$ ) and living arrangements (with parents: $40 \%$; with partner: $23 \%$ ) due to the older age of the sample at second follow-up. However, we did not find selective attrition due to age, gender, geographic distribution, and cannabis or ecstasy outcomes between the baseline and the second follow-up investigation. Detailed descriptions of the EDSP sample design and field procedures have been presented elsewhere (see Wittchen et al., 1998b; Lieb et al., 2000).

\subsection{Diagnostic assessment}

The diagnostic assessment was based on the computer-assisted version of the MunichComposite-International- Diagnostic-Interview (DIA-X/M-CIDI; Wittchen, 1994; Wittchen and Pfister, 1997), an updated version of the World Health Organization's CIDI version 1.2 (WHO, 1990, 1992). The M-CIDI allows for the standardized assessment of symptoms, syndromes, and diagnoses of a wide range of DSM-IV disorders along with information about onset, duration, and severity (APA, 1994). Reliability and validity for assessing substance use have been described elsewhere (Lachner et al., 1998; Reed et al., 1998; Wittchen et al., 1998a). The M-CIDI is supplemented by a separate response booklet, which includes several scales and questionnaires for assessing relevant psychological constructs. Highly trained clinical interviewers - the majority of them were clinical psychologists carried out the interviews face-to-face and mostly in respondents' homes. At baseline, lifetime and 12-month disorders and substance use were assessed with the M-CIDI. For the two follow-up investigations, the M-CIDI was modified to cover the 12-month period prior to the follow-up interview as well as the remaining interval between the investigations (interval-version).

Cannabis and ecstasy use as well as the ages of first onset of cannabis and ecstasy use were assessed in the drug-section of the M-CIDI. Questions about the use of drugs were introduced by a commitment probe, in which each person was asked whether he or she was willing to respond to these questions openly. One hundred and two participants denied this question, therefore, the data for the complete section were not analysed. We report on $\mathrm{N}=2446$ subjects that completed the section with regard to the entire study period until the second follow-up. The drug section continued with a list of names grouped by eight types of substances (e.g., cannabis products, opioids). The respondent was asked whether he or she had ever taken one of the substances presented on these respondents lists. If so, the section continued with a further assessment of lifetime and 12-month quantity and frequency of use as well as associated abuse or dependence symptoms. Details have been described elsewhere (Lachner et al., 1998; Perkonigg et al., 1998; Wittchen et al., 1998b).

Ecstasy use was assessed in each wave using the CIDI respondent list, counting all "ecstasy" reports by the subject. It should be noted, however, that the subjects' reports about ecstasy might not be pharmacologically correct. Given the impossibility of knowing precisely the 
chemically active ingredients of a market drug, accurate assessments in community samples are necessarily impossible.

Cannabis and ecstasy use is defined as use of the respective substance at least once in the described time period. Reported lifetime prevalence at baseline denotes the weighted rate of users in their lifetime until baseline. Follow-up incidence is defined as the rate of first-time users during the follow-up period (T0 to T2) among non-users at baseline. For respondents who were 14- to 17-year-old at baseline, the follow-up status was assessed with the aggregated information from the first and second follow-up interviews. For respondents older than 17 years at baseline, information on the total follow-up period came from the second follow-up interview. Twelve-month prevalence at follow-up refers to the rate of users during the year preceding the second follow-up. Cumulative lifetime prevalence results from aggregating all information from baseline and both follow-up waves, meaning the rate of lifetime users until second follow-up. Cannabis use frequency at baseline is defined in line with WHO-CIDI conventions (Lachner et al., 1998; Sydow et al., 2001; WHO, 1990; Wittchen, 1994; Wittchen et al., 1998a) considering four mutually exclusive patterns of cannabis use (never; 1 time; $2-4$ times; 5 or more times) as the highest lifetime consumption status at baseline. Additionally, the category "5 or more times" was subdivided into "peak time use 1 or 2 times a week" and "peak time use more than twice a week".

"Drug availability" is defined and assessed at baseline and at second follow-up. At baseline the variable "availability of ecstasy 6 months prior to baseline" was used. At second followup, availability was operationalized with the question "How easily could you get ecstasy?" corresponding to a "perceived" availability of ecstasy. Response categories were: "within 2-3 h", "within 24 h", and "within more than 1 day". Response "not at all" was defined as reference.

\subsubsection{Assessment of control variables}

Regular nicotine and alcohol use were included as control variables in logistic regression analyses. In the M-CIDI, regular nicotine use is defined as daily smoking over a period of 4 weeks, and regular alcohol use is defined as drinking alcohol at least three times a week in the period of peak lifetime use. More details concerning the assessment of alcohol and nicotine use have been described elsewhere (Holly and Wittchen, 1998; Nelson and Wittchen, 1998a,b; Sonntag et al., 2000; Zimmermann et al., 2003).

Antisocial behavior prior to age 13 according to the criteria of DSM-IV was assessed at second follow-up by means of the German version of the SKID-II questionnaire and interview concerning antisocial personality disorder (Fydrich et al., 1997; Wittchen et al., 1997).

The included sociodemographic variables school education, financial situation, socioeconomic status, and residential area were assessed at baseline in the M-CIDI sociodemographic section (Lieb et al., 2000).

\subsection{Statistical analyses}

Associations were estimated by odds ratios (OR) based on logistic regressions. Prospective analyses were performed to examine associations between baseline cannabis use or cannabis use frequency, respectively, in predicting availability of ecstasy at second follow-up. These analyses are exclusively based on the subsample of respondents, to whom ecstasy was not available at baseline and who never used ecstasy in their life until second follow-up. 
Moreover, prospective models were used to investigate associations of lifetime cannabis use as well as availability of ecstasy at baseline and actual first onset of ecstasy use during followup (T0-T2) among those who had never used ecstasy until baseline. We have done this by testing cannabis use and availability of ecstasy separately and also together in one model controlling for each other.

Four mutually exclusive groups were defined by cannabis use (yes/no) and availability of ecstasy (yes/no) at baseline. Logistic regression analyses were performed to examine the associations between these four groups in predicting first onset of ecstasy use in the subset of respondents who had never used ecstasy until baseline.

All analyses were controlled for age, gender, lifetime regular alcohol use at baseline, regular smoking at baseline, antisocial behavior prior to age 13, and sociodemographic variables. Only results based on analyses including controls are reported in the present paper. This procedure was done because a literature review as well as preliminary analyses have shown that these variables are related to the predictors "cannabis use" or "availability of ecstasy" at baseline as well as to the outcomes "availability of ecstasy at follow-up" and "onset of ecstasy use during follow-up" (results available on request; Degenhardt et al., 2001; Fergusson and Horwood, 2000; Lynskey et al., 1998; SAMHSA, 2004).

Age-specific cumulative lifetime incidences for ecstasy use were estimated with the KaplanMeier method using age of onset information (Anderson and Keiding, 1996). The relation between prior cannabis use and later onset of ecstasy use was examined by using survival analysis with time-dependent covariates. The time-dependent covariate was defined as having used cannabis prior to time $t$ (here the age). Additionally, this was done stratified by availability of ecstasy at baseline. Differences were tested with hazard ratios (HR) from the Cox regression model (Therneau and Grambsch, 2000).

The data were weighted to adjust for differential probabilities of selection by age and for differential response rates based on the census population distribution of age, gender, and geographic distribution at baseline (Wittchen et al., 1998b). Drop-out between baseline and follow-up (including cases unwilling to answer the questions of the M-CIDI drug section) was not markedly related to these three variables. A significant high rate of drop-out between baseline and second follow-up was observed among subjects with nicotine dependence (OR = $1.3 ; 95 \% \mathrm{CI}=1.1-1.7)$ and dysthymia $(\mathrm{OR}=2.1 ; 95 \% \mathrm{CI}=1.2-3.7)$. All statistical analyses were carried out with the STATA (Stata Corp., 2001) software package. The Huber-White sandwich method for weighted data was used to adjust statistical inference for the weighting of the data (Royall, 1986).

\section{Results}

\subsection{Prevalences and incidences of cannabis and ecstasy use}

At baseline, $34.2 \%$ of the baseline sample reported lifetime cannabis use (Table 1). Four years later at second follow-up, $46.6 \%$ had used cannabis at least once in his/her life. Actual use during the 12 months preceding the second follow-up was reported by $25.4 \%$ of the respondents.

While at baseline the prevalence of lifetime ecstasy use was $4.8 \%$, the rate of ecstasy users doubled (9.1\%) over the 4-year follow-up period. Actual use during the past 12 months before the second follow-up was observed in $2.7 \%$ of the respondents, meaning that almost two-third 
of all lifetime ecstasy users did not use ecstasy in the past 12 months. Almost all lifetime ecstasy users $(>90 \%)$ had also used cannabis at least once until baseline $(91.6 \%)$ as well as until follow-up 4 years later $(93.7 \%)$. In contrast, over $80 \%$ of all cannabis users reported no concomitant ecstasy use (baseline: $87.3 \%$; follow-up: $81.7 \%$ ).

Among those reporting first onset of ecstasy use during follow-up, most had used cannabis until baseline prior to the use of ecstasy $(69.8 \% ; n w=75)$. Conversely, only $0.7 \%(n w=2)$ among those with incident cannabis use during follow-up reported prior ecstasy use until baseline (results not shown in table).

Males had higher prevalences and incidences of cannabis and ecstasy use than females (Range OR women/men: $0.5-0.7$, for all $\mathrm{P}<0.05)$ except for lifetime ecstasy use at baseline $(\mathrm{OR}=$ $0.6 ; 95 \% \mathrm{CI}=0.3-1.0)$ and incident ecstasy use $(\mathrm{OR}=0.8 ; 95 \% \mathrm{CI}=0.4-1.2)$. At baseline, but not at follow-up, the older birth cohort (1970-77) revealed higher rates for lifetime cannabis (older versus younger: 40.3 versus $19.4 \%$; $\mathrm{OR}=2.9 ; 95 \% \mathrm{CI}=2.3-3.5$ ) and ecstasy use (older versus younger: 6.0 versus $1.7 \%$; $\mathrm{OR}=3.7 ; 95 \% \mathrm{CI}=1.9-6.9$ ) compared to the younger birth cohort (1977-81).

\subsection{Cumulative lifetime incidence of ecstasy use by prior cannabis use}

Across all age groups, cumulative lifetime incidences of ecstasy use were considerably higher among ecstasy users with, as compared to those without prior cannabis use (Fig. 1: HR=10.0; $95 \% \mathrm{CI}=6.8-14.7)$. First ecstasy use was rarely reported before the age of 14 years. After that age, there was a steep increase of ecstasy use among prior cannabis users, but only a slight increase among respondents without prior cannabis use. For example, until the age of 21 years $30 \%$ and until the age of 28 years $35 \%$ of respondents with prior cannabis use reported first use of ecstasy; among respondents without prior cannabis use the cumulative incidences never exceeded the $5 \%$ rate.

\subsection{Availability of ecstasy}

At baseline, $96.8 \%$ of all respondents reported to have no availability of ecstasy; only $3.2 \%$ reported an ecstasy availability during the past 6 months (Table 2). Among all nonusers of ecstasy, the rate for availability was $2.3 \%(\mathrm{nw}=53)$ and among users of ecstasy $22.2 \%(\mathrm{nw}=$ 26) (rates not shown in table). Among ecstasy non-users without concomitant cannabis use, availability rate was $1.8 \%$, among those with cannabis use $3.4 \%(\mathrm{OR}=2.1 ; 95 \% \mathrm{CI}=1.0$ 4.3). The respective rates for ecstasy users were 19.5 and $22.5 \%(\mathrm{OR}=0.9 ; 95 \% \mathrm{CI}=0.1-$ 5.7).

At second follow-up, substantially higher rates for the availability of ecstasy were found in the total sample $(29.1 \%)$ and in both the subgroup of ecstasy non-users $(25.3 \%$, nw $=565)$ and of ecstasy users $(66.5 \%, \mathrm{nw}=149)$ (rates not shown in table). Among non-users of ecstasy, only $0.8 \%$ without cannabis use reported ecstasy availability compared to $59.4 \%$ with cannabis use $(\mathrm{OR}=238.1 ; 95 \% \mathrm{CI}=112.9-502.0)$. Corresponding rates among ecstasy users were $27.7 \%$ and $69.1 \%(\mathrm{OR}=6.2 ; 95 \% \mathrm{CI}=1.4-26.5)$.

\subsection{Baseline cannabis use as predictor for subsequent availability of ecstasy at follow-up}

Excluding respondents with ecstasy use, $15.3 \%$ of cannabis non-users at baseline reported to have had access to ecstasy at follow-up. In contrast, the availability rate among baseline users of cannabis was $48.7 \%$ (Table 3 : $\mathrm{OR}=6.4 ; 95 \% \mathrm{CI}=4.7-8.7$ ). Furthermore, an increasing 
frequency of cannabis use at baseline was strongly related to a monotonously increasing proportion of respondents to whom ecstasy was available at follow-up. All analyses have been controlled for confounders.

\subsection{Baseline cannabis use and availability of ecstasy as predictors for subsequent onset of ecstasy use during follow-up}

Table 4 reveals that baseline cannabis use $(\mathrm{OR}=6.4 ; 95 \% \mathrm{CI}=3.6-11.0)$ as well as availability $(\mathrm{OR}=1.5 ; 95 \% \mathrm{CI}=1.4-5.2)$ were both significant predictors for the first onset of ecstasy use during follow-up, if tested in separate models. These associations are significant in the logistic regression model, even though we controlled for a number of confounders. The conditional probability of reporting incident ecstasy use (not reported in table) was lowest in the "no cannabis/no availability" and the "no cannabis/availability" groups (both 2\%). Considerable higher probabilities resulted for the cannabis use groups with $10 \%$ for those without and $14 \%$ for those with ecstasy availability.

In the adjusted model, testing simultaneously the impact of prior cannabis use and availability of ecstasy, the association with availability is attenuated (OR adj. $=1.2 ; 95 \% \mathrm{CI}=0.3-3.9$ ) and not significant anymore.

\subsection{Cumulative lifetime incidence of ecstasy use by prior cannabis use and availability of ecstasy at baseline}

Fig. 2 reveals highest cumulative incidences of first ecstasy use among cannabis users (prior to ecstasy use) and with ecstasy availability at baseline (group 4). For these respondents, the period with the highest risk of starting ecstasy use was between 14 and 22 years with cumulative incidences increasing up to almost $70 \%$ until age 28 . The second highest curve represents those with primary cannabis use but without availability of ecstasy at baseline (group 3). The high-risk period for first onset of ecstasy use was between 14 and 19 years. At age 28 , only about $30 \%$ of this group's young adults reported to have started ecstasy use. Cumulative incidences for group 3 were slightly, but not significantly higher than those for the group with cannabis non-users but with access to ecstasy (group 2$)(\mathrm{HR}=1.5 ; 95 \% \mathrm{CI}=$ 0.6-3.2). The lowest incidence curve resulted for respondents without cannabis use and without availability (group 1) (Range $\mathrm{HR}=6.9-26.3$; for all $\mathrm{P}<0.05$ ), reaching at no age a level over $5 \%$.

\section{Discussion}

Within the context of the "concept of stages" describing a regular sequence in the stages of drug involvement (e.g., Brook et al., 1992; Cohen and Sas, 1997; Ellickson et al., 1992; Hall et al., 2001; Kandel and Faust, 1975; Kandel et al., 1992; Yamaguchi and Kandel, 1984a,b), to our knowledge this is the first study especially focusing on the role of cannabis use for the availability of ecstasy as a possible pathway into subsequent ecstasy use in a community study with a strict prospective design.

With regard to the three main questions of the paper, we found that (1) consistent with the stages theory most incident ecstasy users reported previous cannabis use, but only $1 \%$ among incident cannabis users reported prior ecstasy use. Cannabis use predicts the onset of ecstasy use, confirming cannabis use as a risk factor for ecstasy use. (2) Considering the role of ecstasy availability as a relevant factor for this relationship, prospective analyses revealed that baseline cannabis users had a substantially higher probability of having access to ecstasy at 
follow-up than cannabis non-users. This association showed a "dose-response relationship": the higher the frequency of cannabis use at baseline, the more likely the availability of ecstasy at follow-up. (3) Baseline cannabis use as well as ecstasy availability were significant predictors for the first onset of ecstasy use during follow-up if tested in separate models. In the adjusted model, testing simultaneously the impact of prior cannabis use and ecstasy availability, the association with availability attenuated and lost its significance. So, cannabis use appeared to be the relevant predictor. Nevertheless, the effects observed in our survival analyses with higher case numbers suggest that ecstasy availability might increase the risk of first onset of ecstasy use among cannabis users and cannabis non-users as well.

Before these findings are discussed, some limitations should be highlighted: (1) The assessment of availability of ecstasy was based on self-reports by using different items at baseline and at follow-up with the baseline assessment representing an "ambient" and the follow-up assessment representing a "perceived" availability of ecstasy. (2) At baseline, the availability was only assessed for the past 6 months and at follow-up for the point of time at assessment with no period specified. This could have resulted in lower availability rates and conservative findings. (3) Due to small numbers of individuals with access to ecstasy at baseline, results of our prospective analyses considering the onset of ecstasy use during follow-up as outcome should be handled with care. (4) The analyses in the present study were controlled for a range of important variables (sociodemographic, substance use, etc.).

However, there is a range of other factors that could not be considered (e.g., genetic factors), but that could also have had an impact on the presented results.

With these limitations in mind, we address the cannabis gateway concept with focus on ecstasy availability as a possible pathway into ecstasy use: It is noteworthy that all reported effects are evident even if controlled for age, gender, a range of sociodemographic factors, deviant behavior as well as regular smoking and alcohol use. Furthermore, on the one hand, the weak association between ecstasy availability and later first ecstasy use attenuated after additional control for baseline cannabis use. On the other hand, the association between baseline cannabis use and later first ecstasy use remained strong with only a slight reduction if controlling for ecstasy availability. The latter finding is partially consistent with findings by Fergusson and Horwood (2000), who could demonstrate an even stronger impact of a social context factor compared to our findings. They found associations between cannabis use and onset of other forms of illegal drug use to be strong, even though they controlled for a range of confounding factors. After inclusion of affiliation with drug using peers as a mediator, the association was considerably reduced, but nevertheless the model remained significant. However, in accordance with Fergusson and Horwood (2000) the interpretation of our results also indicates the relevance of additional pathways other than the availability of ecstasy. Such other factors that might play a role in the possible causal link between cannabis use and ecstasy use could be, for instance, neuronal sensitization processes (Cadoni et al., 2001; Kandel, 2003; McCoun, 1998; Tanda and Goldberg, 2003; Tanda et al., 1997; Wickelgren, 1997) or the disinhibition to experiment with illegal drugs other than cannabis (Fergusson and Horwood, 2000; McCoun, 1998). The association may also be explained non-causally by underlying third factors (e.g., drug-taking disposition, correlated genetic factors), which were not controlled for in our study and which could determine the probability of using cannabis as well as ecstasy at every age (Agrawal et al., 2004; Morral et al., 2002; Pudney, 2003).

To conclude, we could demonstrate in a prospective community study of adolescents and young adults that cannabis use is a powerful risk factor for subsequent first onset of ecstasy use. On the basis of the presented data, this relation cannot be sufficiently explained by the 
increased availability of ecstasy. The state of availability as a potential mediator, however, needs further investigation in studies designed more specifically to test this hypothesis.

Table 1

Prevalence and incidence of cannabis and ecstasy use $(N=2446)$

\begin{tabular}{|c|c|c|c|c|c|c|c|c|}
\hline & \multirow{2}{*}{\multicolumn{2}{|c|}{$\frac{\text { Baseline }}{\text { Lifetime }}$}} & \multicolumn{6}{|c|}{ Follow-Up } \\
\hline & & & \multicolumn{2}{|c|}{ Incidence $\mathrm{T} 1+\mathrm{T} 2$} & \multicolumn{2}{|c|}{ 12-Months T2 } & \multicolumn{2}{|c|}{ cum Lifetime T0-T2 } \\
\hline & $n_{w}^{*}$ & $\% w_{w}{ }^{2}$ & $n_{w}^{*}$ & $\% w^{*}$ & $n_{u}{ }^{a}$ & $\% w^{3}$ & $n_{*}{ }^{2}$ & $\% w^{*}$ \\
\hline No cannabis use & 1614 & 65.8 & - & - & 1829 & 74.6 & 1310 & 53.4 \\
\hline Cannabis use & 838 & 34.2 & 304 & 18.9 & 623 & 25.4 & 1142 & 46.6 \\
\hline No use of ecstasy among cannabis users & 731 & $87.3^{\mathrm{b}}$ & - & - & 561 & $90.1^{\mathrm{c}}$ & 932 & $81.7^{4}$ \\
\hline Ecstasy use among cannabis users & 107 & $12.7^{\mathrm{b}}$ & - & - & 62 & $9.9 \mathrm{c}$ & 209 & $18.3^{\mathrm{d}}$ \\
\hline Men & 486 & 39.8 & 176 & 239 & 387 & 31.7 & 661 & 54.2 \\
\hline Women & 352 & 28.6 & 128 & 14.6 & 236 & 19.2 & 480 & 39.5 \\
\hline Birth cohort 1977-81 & 140 & 19.4 & 191 & 32.9 & 252 & 35.0 & 331 & 45.9 \\
\hline Birth cohort $1970-77$ & 698 & 40.3 & 113 & 11.0 & 371 & 21.4 & 811 & 46.8 \\
\hline No ecstasy use & 2335 & 95.3 & - & - & 2386 & 97.3 & 2228 & 90.9 \\
\hline Ecstasy use & 116 & 4.8 & 107 & 4.6 & 66 & 2.7 & 224 & 9.1 \\
\hline No use of cannabis among ecstasy users & 10 & $8.4^{e}$ & - & - & 4 & $6.1^{r}$ & 14 & 6.38 \\
\hline Cannabis use among ecstasy users & 107 & $91.6^{6}$ & - & - & 62 & $93.9^{f}$ & 209 & $93.7^{8}$ \\
\hline Men & 71 & 5.8 & 60 & 52 & 44 & 3.6 & 130 & 10.7 \\
\hline Women & 46 & 3.7 & 47 & 4.0 & 22 & 1.8 & 93 & 7.5 \\
\hline Birth cohort 1977-81 & 12 & 1.7 & 60 & 8.4 & 31 & 4.3 & 72 & 10.0 \\
\hline Birth cohort $1970-77$ & 104 & 6.0 & 48 & 29 & 35 & 2.0 & 152 & 8.8 \\
\hline
\end{tabular}

Since the $n_{w}$-values have been rounded to the nearest whole number, the sum of the individual $n_{w}$-values does not equal the rounded total $n_{w}$.

$n_{\mathrm{s}}$. weighted number of respondents; $\%$ w. weighted percentage.

b Lifetime ecstasy non-use or use, respectively, among lifetime cannabis users until baseline.

c 12-month ecstasy non-use or use, respectively, among cannabis users in the 12 months prior to second follow-up.

a Cumulative lifetime ecstasy non-use or use, respectively, among cumulative lifetime cannabis users until second follow-up.

c Lifetime cannabis non-use or use, respectively, among lifetime ecstasy users until baseline.

(12-mouth cannabis non-use or use, respectively, among ecstasy users in the 12 months prior to second follow-up.

8 Cumulative lifetime cannabis non-use or use, respectively, among cumulative lifetime ecstasy users until second follow-up.

Table 2

Availability of ecstasy among ecstasy users with and without cannabis use at baseline and at second follow-up

\begin{tabular}{|c|c|c|c|c|}
\hline \multirow[t]{2}{*}{ Lifetime substance use at baseline } & \multicolumn{2}{|c|}{ NO $\left(n_{w}=2373 ; \% \%_{w}=96.8\right)$} & \multicolumn{2}{|c|}{$\operatorname{YES}\left(n_{w}=79 ; \%_{w}=3.2\right)$} \\
\hline & $n_{w}^{*}$ & $\%{ }_{w}^{*}$ & $n_{w^{*}}{ }^{3}$ & $\%_{w}{ }^{a}$ \\
\hline \multicolumn{5}{|l|}{ No ecstasy use $\left(n_{w}=2335\right)$} \\
\hline Cannabis use & 706 & 96.6 & 25 & 3.4 \\
\hline \multicolumn{5}{|l|}{ Ecstasy use $\left(n_{s}=116\right)$} \\
\hline No cannabis use & 8 & 80.5 & 2 & 19.5 \\
\hline Cannabis use & \multicolumn{4}{|c|}{ Availability of ecstasy at baseline } \\
\hline \multirow[t]{3}{*}{ Cum. lifetime substance use at second follow-up } & \multicolumn{4}{|c|}{ Availability of ecstasy at second follow-up } \\
\hline & \multicolumn{2}{|c|}{ NO $\left(n_{u}=1739 ; \%_{w}=70.9\right)$} & \multicolumn{2}{|c|}{$\operatorname{YES}\left(n_{w}=714 ; \%_{w}=29.1\right)$} \\
\hline & $\overline{n_{*}{ }^{a}}$ & $\% w_{w}{ }^{3}$ & $\overline{n_{w}}$ & $\%_{\mu}{ }^{a}$ \\
\hline \multicolumn{5}{|l|}{ Ecstasy use $\left(n_{s}=224\right)$} \\
\hline No cannabis use & 10 & 72.4 & 4 & 27.7 \\
\hline Cannabis use & 65 & 30.9 & 145 & 69.1 \\
\hline
\end{tabular}

a $n_{\mathrm{w}}$. weighted number of respondents; $\%$. weighted percentage. 
Table 3

Association (odds ratios) of lifetime cannabis use at baseline and availability of ecstasy at follow-up among ecstasy non-users with no availability of ecstasy at baseline

\begin{tabular}{|c|c|c|c|c|c|c|}
\hline \multirow[t]{3}{*}{ Baseline cannabis use } & \multicolumn{6}{|c|}{ Availability of ecstasy at second follow-upe } \\
\hline & \multicolumn{2}{|l|}{ No } & \multicolumn{2}{|l|}{ YES } & \multirow[t]{2}{*}{$\mathrm{OR}^{\mathrm{b}}$} & \multirow[t]{2}{*}{$(95 \% \mathrm{CD})^{a}$} \\
\hline & $\overline{n_{u}{ }^{2}}$ & $\overline{\%_{u}{ }^{a}}$ & $\overline{n_{w}{ }^{2}}$ & $\% \%_{w^{2}}$ & & \\
\hline $\begin{array}{l}\text { No cannabis use }{ }^{d} \\
\text { Cannabis use }\end{array}$ & $\begin{array}{r}1309 \\
326\end{array}$ & $\begin{array}{l}84.8 \\
51.3\end{array}$ & $\begin{array}{l}235 \\
309\end{array}$ & $\begin{array}{l}15.3 \\
48.7\end{array}$ & $\begin{array}{l}1.0 \\
6.4^{*}\end{array}$ & $(4.7-8.7)$ \\
\hline \multicolumn{7}{|l|}{ Use frequency } \\
\hline No use ${ }^{d}$ & 1309 & 84.8 & 235 & 15.3 & 1.0 & \\
\hline One time use & 97 & 62.2 & 59 & 37.8 & $43^{*}$ & $(2.7-6.7)$ \\
\hline $2-4$ time use & 122 & 53.0 & 108 & 47.0 & $6.1^{*}$ & $(4.1-9.1)$ \\
\hline At least 5 times ( 1 or 2 times a week) & 92 & 45.8 & 109 & 54.2 & $9.2^{*}$ & $(5.9-14.3)$ \\
\hline At least 5 times (more than 2 times a week) & 15 & 31.3 & 33 & 68.8 & $15.6^{*}$ & $(7.8-35.8)$ \\
\hline
\end{tabular}

${ }^{*} n_{\mathrm{w}}$, weighted number of respondents; $\%$ w. weighted percentage; $\mathrm{CI}$, confidence interval

OR, odds ratio of a multiple logistic regression including age, gender, regular alcohol use and regular smoking, antisocial behavior, school education, financial situation, socioeconomic status, residential area.

'Reference group: no availability of ecstasy at second follow-up.

¿ Reference group.

$p<0.05$.

Table 4

Association (odds ratios) of baseline cannabis use (lifecime) and availablity of ecstasy with first ecstasy use during follow-up period (T0-T2)

\begin{tabular}{|c|c|c|c|c|c|c|c|c|}
\hline \multirow[t]{3}{*}{ Baseline cammabis use and ecstasy availability } & \multicolumn{8}{|c|}{ First ecstasy use during follow-up period $f$} \\
\hline & \multicolumn{2}{|l|}{ No } & \multicolumn{2}{|l|}{ YES } & \multirow[t]{2}{*}{$\mathrm{OR}^{\mathrm{b}}$} & \multirow[t]{2}{*}{$(95 \% \mathrm{CI})^{\mathrm{b}}$} & \multirow[t]{2}{*}{ OR adj.b } & \multirow[t]{2}{*}{$(95 \% \mathrm{CT})^{b}$} \\
\hline & $\overline{n_{\mathrm{s}}{ }^{\mathrm{a}}}$ & $\%_{w^{2}}{ }^{2}$ & $\overline{n_{\mathrm{w}}{ }^{\mathrm{a}}}$ & $\% \%_{w}^{2}$ & & & & \\
\hline $\begin{array}{l}\text { No cannabis use } \\
\text { Cannabis use }\end{array}$ & $\begin{array}{r}1572 \\
656\end{array}$ & $\begin{array}{l}98.0 \\
89.8\end{array}$ & $\begin{array}{l}32 \\
75\end{array}$ & $\begin{array}{r}2.0 \\
10.2\end{array}$ & $\begin{array}{l}1.0 \\
6.4^{*}\end{array}$ & $(3.6-11.0)^{6}$ & $6.3^{*}$ & $(3.6-10.9)$ \\
\hline $\begin{array}{l}\text { No availability of ecstasy } \\
\text { Availability of ecstasy }\end{array}$ & $\begin{array}{r}2179 \\
49 \\
\end{array}$ & $\begin{array}{l}95.5 \\
92.4 \\
\end{array}$ & $\begin{array}{r}103 \\
4 \\
\end{array}$ & $\begin{array}{l}4.5 \\
7.6 \\
\end{array}$ & $\begin{array}{l}1.0 \\
1.5^{*}\end{array}$ & $(1.4-5.2)^{\circ}$ & 1.2 & $(0.3-3.9)^{d}$ \\
\hline
\end{tabular}

${ }^{2} n_{w}$, weighted number of respondents; $\%$ weighted percentage

b $\mathrm{OR}$, odds ratio; $\mathrm{CI}$, confidence interval.

' Multiple logistic regression including cannabis use $O R$ availability of ecstasy and related drugs (respectively), and controls

${ }^{4}$ Multiple logistic regression including cannabis use $A N D$ availability of ecstasy and related drugs, and controls.

' Reference group: no lifetime ecstasy use at baseline and during the period berween baseline and second follow-up; all analyses are controlled for age, gender, regular alcohol use, regular smoking, antisocial behavior, school education, financial siruation, socioeconomic status, and residential area.

$* p<0.05$.

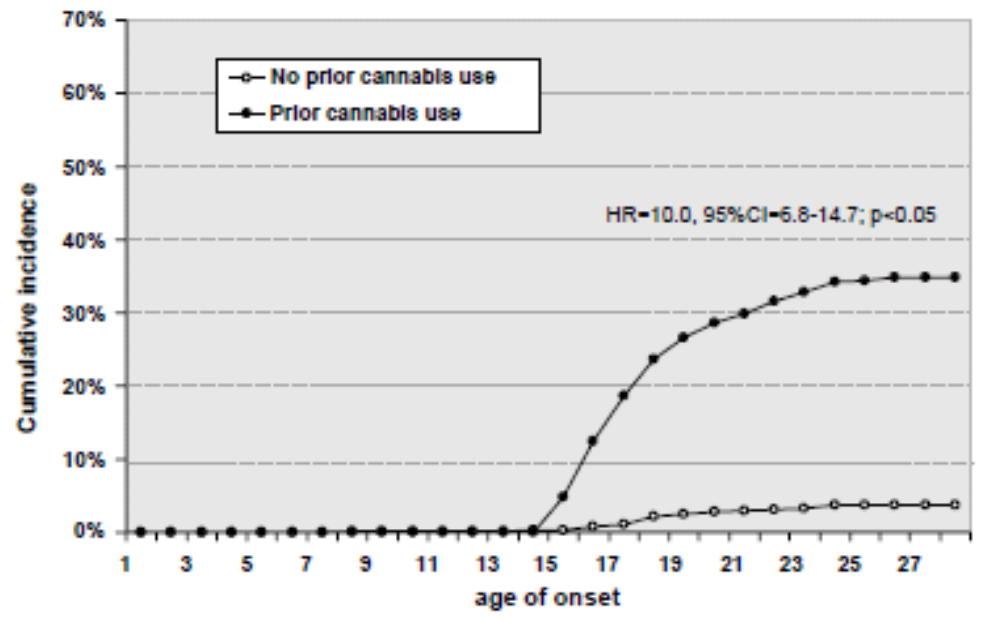

Fig. 1. Cumulative lifetime incidence of ecstasy use by prior cannabis use. 


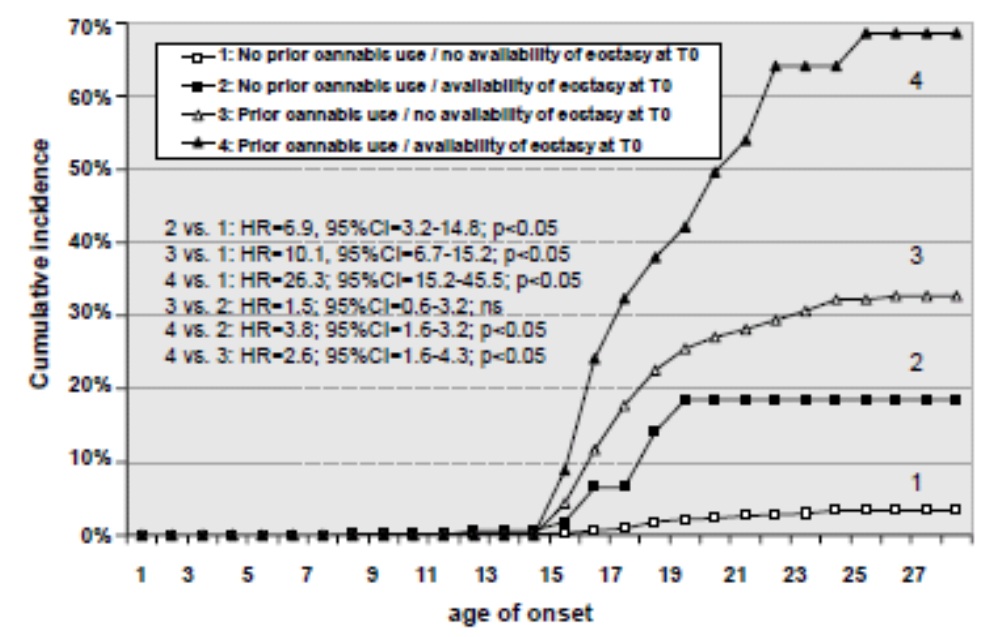

Fig. 2. Cumulative lifetime incidence of ecstasy use by prior cannabis use and availability of ecstasy at baseline.

\section{Acknowledgements}

This work is part of the Early Developmental Stages of Psychopathology (EDSP) Study and is funded by the German Ministry of Research and Technology, project no. 01 EB 9405/6 and 01 EB 9901/6. Principal investigators are Dr. Hans-Ulrich Wittchen and Dr. Roselind Lieb. Current or former staff members of the EDSP group are Dr. Kirsten von Sydow, Dr. Gabriele Lachner, Dr. Axel Perkonigg, Dr. Peter Schuster, Dipl.-Stat. Michael Höfler, Mag. phil. Esther Beloch, Dr. Martina Fuetsch, Dipl.Psych. Elzbieta Garczynski, Dr. Barbara Isensee, Dr. Marianne Mastaler, Dr. Chris Nelson, Dipl.Psych. Agnes Nocon, Dipl.-Inf. Hildegard Pfister, Dr. Victoria Reed, Dipl.-Psych. Andrea Schreier, Dipl.-Soz. Barbara Spiegel, Dipl.-Psych. Dilek Türk, Dipl.-Psych. Antonia Vossen, Dr. Ursula Wunderlich and Dr. Petra Zimmermann. Scientific advisors are Dr. Jules Angst (Zurich), Dr. Jürgen Margraf (Basel), Dr. Günther Esser (Potsdam), Dr. Kathleen Merikangas (NIMH, Bethesda) and Dr. Ron Kessler (Harvard, Boston).We thank Evelyn Kühne, Holmfridur Vilhjalmsdottir and Dzifa Vode for their help in proof-reading this manuscript and the anonymous reviewers for their constructive suggestions to improve the paper. Our special thanks go to the participants of this study.

\section{References}

- Adler, I., Kandel, D., 1981. Cross-cultural perspectives on developmental stages in adolescent drug use. J. Stud. Alcohol 42, 701-715.

- Agrawal, A., Neale, M.C., Prescott, C.A., Kendler, K.S., 2004. Cannabis and other illicit drugs: comorbid use and abuse/dependence in males and females. Behav. Genet. 34 (3), $217-$ 228.

- American Psychiatric Association, 1994. Diagnostic and Statistical Manual of Mental Disorders, fourth ed. APA, Washington, DC.

- Anderson, P.K., Keiding, N., 1996. Survival analysis. In: Armitage, P., David, H.A. (Eds.), Advantages in biometry: 50 Years of the International Biometric Society. John Wiley and Sons, New York, pp. 177-200.

- Anthony, J.C., Warner, L.A., Kessler, R.C., 1994. Comparative epidemiology of dependence on tobacco, alcohol, controlled substances, and inhalants: basic findings from the National Comorbidity Survey. Exp. Clin. Psychopharmacol. 2 (1), 244-268.

- Baumann, A., Phongsavan, P., 1999. Epidemiology of substance use in adolescence: prevalence, trends and policy implications. Drug Alcohol Depend. 55, 187-207.

- Brook, J.S., Hamburg, B.A., Balka, E.B., Wynn, P.S., 1992. Sequence of drug-involvement in African-American and Puerto Rican adolescents. J. Genet. Psychol. 4, 393-410. 
- Cadoni, C., Pisano, A., Solinas, M., et al., 2001. Behavioral sensitization after repeated exposure to delta-9-tetrahydrocannabinol and cross-sensitization with morphine.

Psychopharmacology 158, 259-266.

- Cohen, P., Sas, A., 1997. Cannabis use, a stepping stone to other drugs? The case of Amsterdam. In: Böllinger, L. (Ed.), Cannabis Science/Cannabis Wissenschaft. From Prohibition to Human Right/Von der Prohibition zum Recht auf Genuß. Peter Lang Europäischer Verlag der Wissenschaften, Frankfurt a.M, pp. 49-82, http://www.cedrouva.org/lib/cohen.canasd.pdf.

- Degenhardt, L., Barker, B., Topp, L., 2004. Patterns of ecstasy use in Australia: findings from a national household survey. Addiction 99(2), 187-195.

- Degenhardt, L., Hall, W., Lynskey, M., 2001. The relationship between cannabis use and other substance use in the general population. Drug Alcohol Depend. 64, 319-327.

- Ellickson, P.L., Hays, R.D., Bell, R.M., 1992. Stepping through the drug use sequence: longitudinal scalogram analysis of initiation and regular use. J. Abnorm. Psychol. 101, 441451.

- European Monitoring Centre for Drugs and Drug Addiction, 2003. Annual Report 2003: The state of the drugs problem in the European Union and Norway. Printed in Belgium.

- Fergusson, D.M., Horwood, L.J., 1997. Early onset cannabis use and psychosocial adjustment in young adults. Addiction 92, 279-296.

- Fergusson, D.M., Horwood, L.J., 2000. Does cannabis use encourage other forms of illicit drug use? Addiction 95, 505-520.

- Fydrich, T., Renneberg, B., Schmitz, B., Wittchen, H.-U., 1997. SKIDII - Strukturiertes Klinisches Interview für DSM-IV; Achse II: Persönlichkeitsstörungen Hogrefe, Göttingen.

- Goode, E., 1974. Marijuana use and the progression to dangerous drugs. In: Miller, L. (Ed.), Marijuana: Effects on Human Behavior. Academic Press, New York, pp. 303-338.

- Hall, W., Degenhardt, L., Lynskey, M., 2001. Is cannabis a gateway drug? In: Hall, W., Degenhardt, L., Lynskey, M., (Eds.), The Health and Psychological Effects of Cannabis Use, Monograph Series No. 44 (http://www.health.gov.au/pubhlth/publicat/document/mono44.pdf), 103-106.

- Hall, W., Johnston, L., Donnelly, N., 1999. Epidemiology of cannabis use and its consequences. In: Kalant, H., Corrigall, W., Hall, W., Smart R. (Eds.), The Health Effects of Cannabis. Centre for Addiction and Mental Health, Toronto, Canada, pp. 71-125.

- Hays, R.D., Widman, K.F., Dimatteo, M.R., Stacy, A.W., 1987. Structural equation models of current drug use: are appropriate models so simple(x)? J. Pers. Soc. Psychol. 57, 134-218.

- Holly, A., Wittchen, H.-U., 1998. Patterns of use and their relationship to DSM-IV abuse and dependence of alcohol among adolescents and young adults. Eur. Addict. Res. 4 (1-2), 50-57.

- Huba, G.J., Wingard, J.A., Bentler, P.M., 1981. A comparison of two latent variable causal models of adolescent drug use. J. Pers. Soc. Psychol. 40, 180-193.

- Jansen, K.L., 1999. Ecstasy (MDMA) dependence. Drug Alcohol Depend. 53, 121-124.

- Johnson, B.D., 1973. Marijuana Users and Drug Subcultures. Wiley, New York.

- Kandel, D.B., 2003. Does marijuana use cause the use of other drugs? JAMA 289 (4), 482483.

- Kandel, D.B., Faust, R., 1975. Sequence and stages in patterns of adolescent drug use. Arch. Gen. Psych. 32, 923-932.

- Kandel, D.B., Yamaguchi, K., 1993. From beer to crack: developmental patterns of drug involvement. Am. J. Public Health 83, 851-855.

- Kandel, D.B., Yamaguchi, K., Chen, K., 1992. Stages of progression in drug involvement from adolescence to adulthood: further evidence for the gateway theory. J. Stud. Alcohol 53, 447-457.

- Kraus, L., Augustin, R., 2000. Repräsentativerhebung zum Gebrauch psychoaktiver Substanzen bei Erwachsenen in Deutschland. Sucht 47 (Sonderheft 1), 3-86.

- Lachner, G., Wittchen, H.-U., Perkonigg, A., Holly, A., Schuster, P., Wunderlich, U., Türk, D., Garczynski, E., Pfister, H., 1998. Structure, content and reliability of the MunichComposite International Diagnostic Interview (M-CIDI). Substance use sections. Eur. Addict. Res. 4 (1-2), 28-41. 
- Lieb, R., Isensee, B., von Sydow, K., Wittchen, H.-U., 2000. The early developmental stages of psychopathology study (EDSP): a methodological update. Eur. Addict. Res. 6, 170-182.

- $\quad$ Lieb, R., Schütz, Ch., Pfister, H., von Sydow, K., Wittchen, H.-U., 2002. Mental disorders in ecstasy users: a prospective-longitudinal investigation. Drug Alcohol Depend. 68, 195-207.

- Lynskey, M.T., Fergusson, D.M., Horwood, L.J., 1998. The origins of the correlations between tobacco, alcohol, and cannabis use during adolescence. J. Child. Psychol. Psyc. 39 (7), 995-1005.

- McCoun, R., 1998. In what sense (if any) is marijuana a gateway drug? FAS Drug Policy Analysis Bull. 4. (February), http://www.fas.org/drugs/issue4.htm\#gateway.

- Morral, A.R., McCaffrey, D.F., Paddock, S.M., 2002. Reassessing the marijuana gateway effect. Addiction 97, 1493-1504.

- Nelson, C.B., Wittchen, H.-U., 1998a. DSM-IV alcohol disorders in a general population sample of adolescents and young adults. Addiction 93 (7), 1065-1077.

- Nelson, C.B., Wittchen, H.-U., 1998b. Smoking and nicotine dependence: results from a sample of 14- to 24-year-old in Germany. Europ. Addict. Res. 4 (1-2), 42-49.

- Parrott, A.C., 2001. Human psychopharmacology of ecstasy (MDMA): a review of 15 years empirical research. Human Psychopharmacol. Clinical Experim. 16, 557-577.

- $\quad$ Parrott, A.C., Lees, A., Garnham, N.J., Jones, M., Wesnes, K., 1998. Cognitive performance in recreational users of MDMA or 'ecstasy': evidence for memory deficits. J. Psychopharmacol. 12 (1), 79-83.

- Perkonigg, A., Lieb, R., Höfler, M., Schuster, P., Sonntag, H., Wittchen, H.-U., 1999. Patterns of cannabis use, abuse and dependence over time: incidence, progrssion and stability in a sample of 1228 adolescents. Addiction 94 (11), 1663-1678.

- Perkonigg, A., Lieb, R., Wittchen, H.-U., 1998. Prevalence of use, abuse and dependence of illegal drugs among adolescents and young adults in a community sample. Eur. Addict. Res. 4 (1-2), 58-66.

- Perkonigg, A., Pfister, H., Lieb, R., Bühringer, G., Wittchen, H.-U., 2004. Problematischer Konsum illegaler Substanzen, Hilfesuchverhalten und Versorgungsangebote in einer Region. Suchtmedizin 6 (1), 22-31.

- Pudney, S., 2003. The road to ruin? Sequences of initiation to drugs and crime in Britain. Econ. J. 113, C182-C198.

- $\quad$ Reed, V., Gander, F., Pfister, H., Steiger, A., Sonntag, H., Trenkwalder, C., Hundt, W., Wittchen, H.-U., 1998. To what degree the Composite International Diagnostic Interview (CIDI) correctly identifies DSM-IV disorders? Testing validity issues in a clinical sample. Int. J. Methods Psychiatr. Res. 7, 142-155.

- Robins, L., 1993. Vietnam veterans' rapid recovery from heroin addiction: a fluke or normal expectation? Addiction 88, 1041-1054.

- Royall, R.M., 1986. The effect of sample size on the meaning of significance. Am. Stat. 40, 313-315.

- Schuster, P., Lieb, R., Lamertz, C., Wittchen, H.-U., 1998. Is the use of ecstasy and hallucinogens increasing? Results from a community study. Eur Add Res 4 (1/2), 75-82.

- Smart, R.G., Ogborne, A.C., 2000. Drug use and drinking among students in 36 countries. Addict. Behav. 25 (3), 455-460.

- Smit, F., Monshouwer, K., Verdurmen, J., 2002. Polydrug use among secondary school students: combinations, prevalences and risk profiles. Drug. Educ. Prev. Polic. 9 (4), 355-365.

- Sonntag, H., Wittchen, H.-U., Höfler, M., Kessler, R.C., Stein, M.B., 2000. Are social fears and DSM-IV social anxiety disorder associated with smoking and nicotine dependence in adolescents and young adults. Eur. Psychiatry 15, 67-74.

- StataCorp., 2001. Stata Statistical Software: Release 7.0. Stata Corporation: College Station.

- Substance Abuse and Mental Health Services Administration (SAMHSA), Office of Applied Studies, 2004. The NSDUH report, January 16, (http://www.DrugAbuseStatistics.samhsa.gov).

- Sydow, K. von., Lieb, R., Pfister, H., Höfler, M., Sonntag, H., Wittchen, H.-U., 2001. The natural course of cannabis use, abuse and dependence over 4 years: a longitudinal community study of adolescents and young adults. Drug Alcohol Depend. 64, 347-361. 
- $\quad$ Sydow, K.von., Lieb, R., Pfister, H., Höfler, M., Wittchen, H.-U., 2002. Use, abuse and dependence of ecstasy and related drugs in adolescents and young adults - a transient phenomenon? Results from a longitudinal community study. Drug Alcohol Depend. 66, 147159.

- Tanda, G., Goldberg, S.R., 2003. Cannabinoids: reward, dependence, and underlying neurochemical mechanisms: a review of recent preclinical data. Psychopharmacology 169 (2), 115-134.

- Tanda, G., Pontieri, F.E., Di Chiara, G.D., 1997. Cannabinoid and herion activation of mesolimbic dopamine transmission by a common $\mu 1$ opioid receptor mechanism. Science 276, 2048-2050.

- Therneau, T.M., Grambsch, P.M., 2000. Modelling Survival Data. Springer, New York.

- Thomasius, R., Schmolke, M., Kraus, D., 1997. MDMA ("Estasy")-Konsum: ein Überblick zu psychiatrischen und medizinischen Folgen. Fortschritte der Neurologie/Psychiatrie 65, 49-61.

- Tuchtenhagen, F., Daumann, J., Norra, C., Gobbele, R., Becker, S., Pelz, S., Sass, H., Buchner, H., Gouzoulis-Mayfrank, E., 2000. High intensity dependence of auditory evoked dipole source activity indicates decreased serotonergic activity in abstinent ecstasy (MDMA) users. Neuropsychopharmacology 22 (6), 608-617.

- Wagner, F., Anthony, J.C., 2002. Into the world of illegal drug use: exposure opportunity and other mechanisms linking the use of alcohol, tobacco, marijuana, and cocaine. Am. J. Epidemiol. 155, 918-925.

- Wickelgren, I., 1997. Marijuana: harder than thought? Science 276, 1967-1968.

- Wittchen, H.-U., 1994. Reliability and validity studies of the WHO-Composite International Diagnostic Interview (CIDI): a critical review. J. Psychiatr. Res. 28, 57-84.

- Wittchen, H.-U., Lachner, G., Wunderlich, U., Pfister, H., 1998a. Testretest reliability of the computerized DSM-IV version of the Munich-Composite International Diagnostic Interview (M-CIDI). Soc. Psychiatry Psychiatr. Epidemiol. 33, 568-578.

- Wittchen, H.-U., Perkonigg, A., Lachner, G., Nelson, C.B., 1998b. Early developmental stages of psychopathology study (EDSP): objectives and design. Eur. Addict. Res. 4, 18-27.

- Wittchen, H.-U., Pfister, H. (Eds.), 1997. DIA-X-Interviews: Manual für Screening-Verfahren und Interview; Interviewheft Längsschnittuntersuchung (DIA-X-Lifetime); Ergänzungsheft (DIA-X-Lifetime); Interviewheft Querschnittuntersuchung (DIA-X-12 Monate); Ergänzungsheft (DIA-X-12Monate); PC-Programm zur Durchführung des Interviews (Längsund Querschnittuntersuchung); Auswertungsprogramm. Swets and Zeitlinger, Frankfurt.

- Wittchen, H.-U., Zaudig, M., Fydrich, T., 1997. SKID. Strukturiertes Klinisches Interview für DSM-IV. Achse I und II. Handanweisung. Hogrefe, Göttingen.

- World Health Organization, 1990. Composite International Diagnostic Interview (CIDI): (a) CIDI-Interview (version 1.0), (b) CIDI-User Manual, (c) CIDI-Training Manual (d) CIDIComputer Programs, World Health Organisation, Geneva.

- World Health Organization, 1992. Alcohol use disorders and associated disabilities interview schedule: Alcohol/drug revised. World Health Organization, Geneva.

- World Health Organization, 1996. Worldwide amphetamine abuse: a particular concern for WHO, World Health Organization press release WHO/77 Rev., 13 November 1996. World Health Organization, Geneva.

- Yamaguchi, K., Kandel, D., 1984a. Patterns of drug use from adolescence to young adulthood: II. Sequences of progression. Am. J. Public Health 74, 668-672.

- Yamaguchi, K., Kandel, D., 1984b. Patterns of drug use from adolescence to young adulthood: III. Predictors of progression. Am. J. Public Health 74, 668-672.

- Zimmermann, P., Wittchen, H.-U., Höfler, M., Lieb, R., 2003. Primary anxiety disorders and the development of subsequent alcohol use disorders: a four-year community study of adolescents and young adults. Psychol. Med. 33, 1211-1222. 